\title{
Morphological features and variations of temperature in the upper thermosphere simulated by a whole atmosphere GCM
}

\author{
H. Fujiwara ${ }^{1}$ and Y. Miyoshi ${ }^{2}$ \\ ${ }^{1}$ Department of Geophysics, Graduate School of Science, Tohoku University, Sendai, Japan \\ ${ }^{2}$ Department of Earth and Planetary Sciences, Faculty of Sciences, Kyushu University, Fukuoka, Japan
}

Received: 16 February 2009 - Revised: 19 October 2009 - Accepted: 27 January 2010 - Published: 8 February 2010

\begin{abstract}
In order to illustrate morphological features and variations of temperature in the upper thermosphere, we performed numerical simulations with a whole atmosphere general circulation model (GCM) for the solar minimum and geomagnetically quiet conditions in March, June, September, and December. In previous GCMs, tidal effects were imposed at the lower boundaries assuming dominant diurnal and semi-diurnal tidal modes. Since the GCM used in the present study covers all the atmospheric regions, the atmospheric tides with various modes are generated within the GCM. The global temperature distributions obtained from the GCM are in agreement with ones obtained from NRLMSISE-00. In addition, the GCM also represents localised temperature structures which are superimposed on the global day-night distributions. These localised structures, which vary from hour to hour, would be observed as variations with periods of about $2-3 \mathrm{~h}$ at a single site. The amplitudes of the $2-3 \mathrm{~h}$ variations are significant at high-latitude, while the amplitudes are small at low-latitude. The diurnal temperature variation is more clearly identified at lowlatitude than at high-latitude. When we assume the same high-latitude convection electric field in each month, the temperature calculated in the polar cap region shows diurnal variation more clearly in winter than in summer. The midnight temperature maximum (MTM), which is one of the typical low-latitude temperature structures, is also seen in the GCM results. The MTMs in the GCM results show significant day-to-day variation with amplitudes of several $10 \mathrm{~s}$ to about $150 \mathrm{~K}$. The wind convergence and stream of warm air are found around the MTM. The GCM also represent the meridional wind reversals and/or abatements which are caused due to local time variations of airflow pattern in the low-latitude region.
\end{abstract}

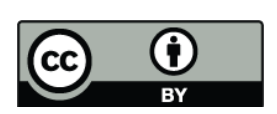

Correspondence to: $\mathrm{H}$. Fujiwara (fujiwara@pat.geophys.tohoku.ac.jp)
Keywords. Meteorology and atmospheric dynamics (Climatology; Thermospheric dynamics; Waves and tides)

\section{Introduction}

From the statistical analysis of the Dynamics Explorer 2 (DE-2) satellite observations, Innis and Conde (2001) showed vertical wind perturbations probably caused by the atmospheric gravity waves in the polar cap region of the upper thermosphere. Their results indicate that the polar cap thermosphere would be filled with disturbances. However, characteristics of the disturbances, e.g., temporal variations, are not known because of sparse thermospheric observations in the region. On the other hand, high speed ion flows and their fluctuations have been observed in the vicinity of the cusp region in the polar F region (e.g., Shepherd et al., 2003). Some studies also suggested significant heat sources (e.g., Lühr et al., 2004; Fujiwara et al., 2007) which would cause temperature, wind, and composition variations in the region. These suggest that there would be various types of disturbances, e.g., waves, localised high temperature, and localised flow, in the polar cap region of the upper thermosphere.

Recently, Miyoshi and Fujiwara (2008) investigated characteristics of the gravity waves in the thermosphere from numerical simulations with a whole atmosphere general circulation model (GCM) which covered all the atmospheric regions, namely, from the ground to the exobase (e.g., Miyoshi and Fujiwara, 2003, 2006; Fujiwara and Miyoshi, 2006). The atmospheric gravity waves were found in the GCM results in the entire thermosphere. The dominant wavelength and frequency of the waves depended on altitude. In addition, they also showed significant activities of the gravity waves in the polar region of the upper thermosphere. Their GCM simulations suggested that the origin of the thermospheric gravity waves would be gravity waves generated in the tropical troposphere and/or secondary gravity waves caused by

Published by Copernicus Publications on behalf of the European Geosciences Union. 
breaking of gravity waves in the mesosphere. The smallscale and short period variations in the thermosphere as simulated by Miyoshi and Fujiwara (2008) were also observed with a high-resolution Fabry-Perot Interferometer (FPI) by Ford et al. (2008).

In the upper thermosphere, the large-scale temperature structure has been characterised by high temperature regions at the dayside low-latitude due to absorption of the solar extreme ultraviolet (EUV) radiation and at the auroral highlatitude due to Joule heating, which can be seen in an empirical model of NRLMSISE-00 (Picone et al., 2002). However, as shown by Innis and Conde (2001), localised (smallscale) structures are also expected to be generated and maintained at any time in the polar cap region of the upper thermosphere. In addition to the high-latitude region, there are some characteristic structures in the low-latitude thermosphere. The midnight temperature maximum (MTM) is the well-known low-latitude thermospheric phenomena (e.g., Colerico and Mendillo, 2002; Meriwether et al., 2008). The MTM would produce characteristic temperature structures, associated pressure bulge, and the neutral wind perturbations. Recent satellite observations also found variations and/or disturbances in the low-latitude upper thermosphere (e.g., Forbes et al., 2008; Oberheide and Forbes, 2008).

Although significant changes in the thermospheric dynamics and composition during/after large energy inputs from the magnetosphere into the polar region have been one of the main research targets, other thermospheric variations, e.g., day-to-day variations and disturbances caused by lower atmospheric effects have not been investigated well. In order to understand morphological features and variations of temperature with localised structures in the upper thermosphere, we perform numerical simulations with a whole atmosphere GCM developed by Miyoshi and Fujiwara (2003) for the solar minimum and geomagnetically quiet conditions. We show the temperature and horizontal wind variations in the upper thermosphere affected by the lower atmosphere (the atmospheric regions below the thermosphere) depending on seasons and latitudes. In particular, localised temperature structures in the polar and low-latitude regions are discussed in the present study.

\section{Model and simulations}

In the present study, we use a general circulation model (GCM) which has been developed as an extension of the middle atmosphere GCM developed at Kyushu University (Miyahara et al., 1993; Miyoshi, 1999). The present version of the GCM was also used by Fujiwara and Miyoshi (2006, 2009). Since the previous works (Miyoshi and Fujiwara, 2003, 2006; Fujiwara and Miyoshi, 2006; and references therein) already described the GCM, the description of the upper atmosphere is briefly mentioned here.
The GCM is a global spectral model with a triangular truncation of T21 (the maximum horizontal wave number is equal to 21 with spatial scale of about $5.6^{\circ}$ in latitude and longitude). The GCM includes 75 vertical levels and covers the regions from the ground surface to the exobase (about $500 \mathrm{~km}$ height for the solar minimum and geomagnetically quiet conditions) with a vertical resolution of 0.4 scale height above the tropopause. In addition to the energy and momentum equations, the continuity equation for the major species $\left(\mathrm{O}, \mathrm{O}_{2}\right.$, and $\left.\mathrm{N}_{2}\right)$ is solved in the thermosphere. The time step for integrating the equations is $100 \mathrm{~s}$. The magnetospheric convection electric field modelled by Volland (1975) and empirical ionosphere based on Chiu (1975), Fuller-Rowell and Evans (1987), and Roble and Ridley (1987) are used to calculate the Joule heating rate, auroral particle heating rate, and ion-drag force during geomagnetically quiet periods. The tilted offset magnetic dipole field is assumed in the GCM.

In order to investigate seasonal temperature variations for the solar minimum and geomagnetically quiet conditions, we perform numerical simulations in cases of a) 1-5 March, b) 1-5 June, c) 1-5 September, and d) 1-5 December, assuming that the cross polar cap potential drop is $30 \mathrm{kV}$ and the F10.7 index is $70 \times 10^{-22} \mathrm{~W} \mathrm{~m}^{-2} / \mathrm{Hz}$ in all the cases.

\section{Results}

Figure 1 shows temperature and horizontal wind distributions at 01:00 UT on a) 1 March, b) 1 September, c) 1 June, and d) 1 December on a constant-pressure surface of about 302$312 \mathrm{~km}$ altitude. Note that the strength of the maximum wind vector is different in each panel. The winds in the mid and low-latitude regions are not so clear in Fig. 1 because the vector scale of the wind is chosen to represent the global wind pattern (particularly strong winds at high-latitudes) and the solar-driven wind is in itself small in the solar minimum condition. These seem to be good examples which represent typical features of global temperature and wind distributions calculated with the whole atmosphere GCM. The global temperature and wind distributions presented here are in agreement with those shown by previous studies (e.g., Rishbeth et al., 2000). On the other hand, localised temperature structures are superimposed on the large-scale ones as seen in Fig. 1a-d. These localised structures result from the lower atmospheric effects (Fujiwara and Miyoshi, 2009). High temperature in the dayside low-latitude and low temperature in the night side are clearly seen in Fig. 1a and b. High temperature regions are prominent in the high-latitude and dayside low-latitude in the summer hemisphere, while low temperature regions appear in the night side high-latitude in the winter hemisphere (Fig. 1c and d). Wavy structures in the vicinity of the solar terminator pointed out by previous studies (Fujiwara and Miyoshi, 2006; Forbes et al., 2008) are seen in the temperatures in Fig. 1c and d (low-latitude regions over Southeast Asia and Africa). In Fig. 1a-d, the 


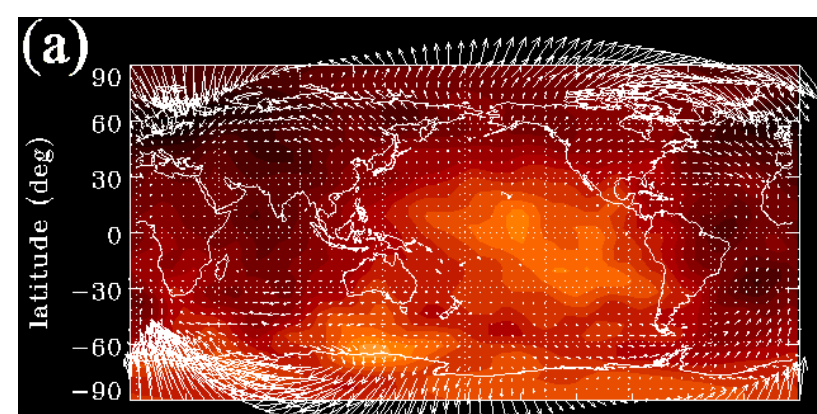

$0 \quad 30 \quad 60 \quad 90 \quad 100450180210240270300330360$
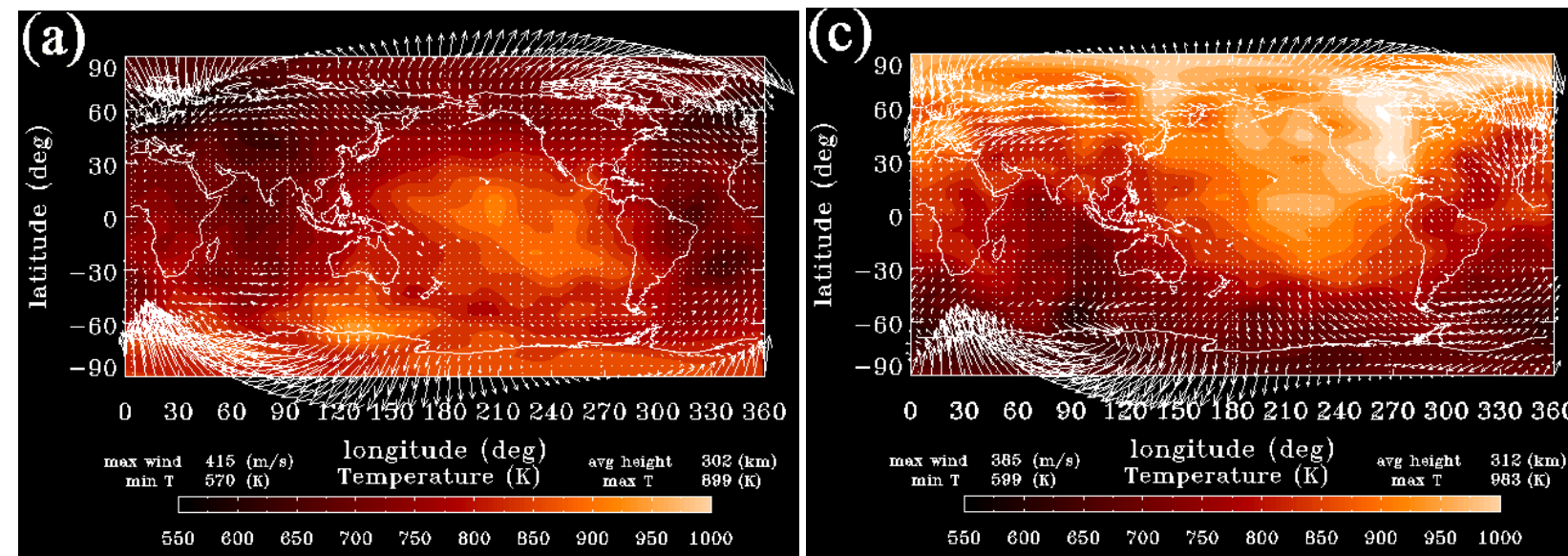

$\begin{array}{llllll}0 & 30 & 60 & 90 & 120 & 150\end{array}$
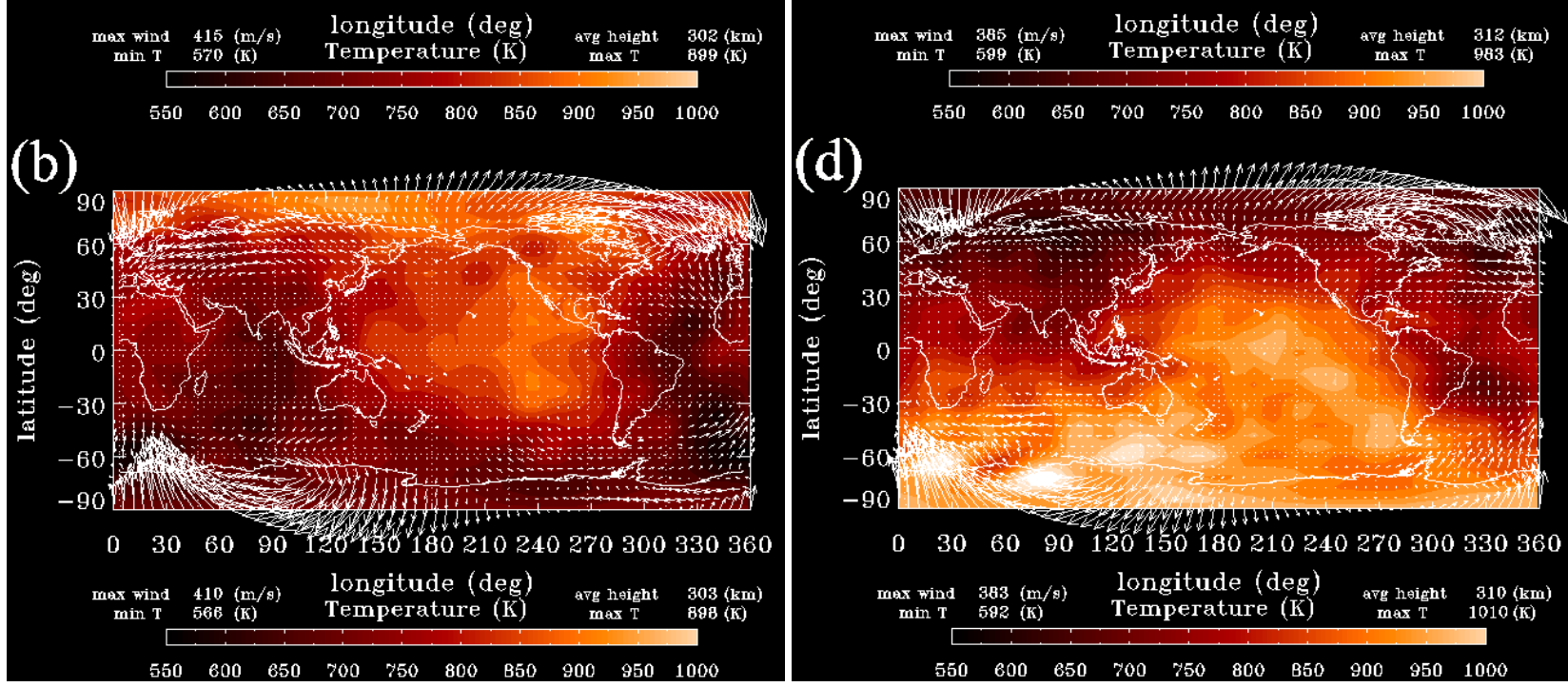

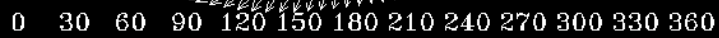

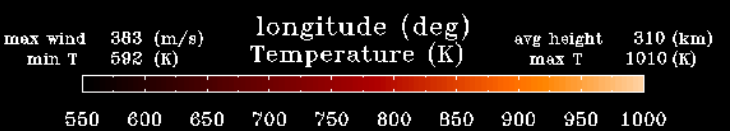

Fig. 1. The global distributions of temperature and horizontal wind on a constant-pressure surface ( $2302-312 \mathrm{~km}$ altitude $)$ at $01: 00 \mathrm{UT}$ in (a) 1 March, (b) 1 September, (c) 1 June, and (d) 1 December. Note that the strength of the maximum wind vector is different in each panel.

maximum/minimum temperature and maximum wind velocity are $899 / 570 \mathrm{~K}$ and $415 \mathrm{~m} \mathrm{~s}^{-1}$ (in March), 983/599 $\mathrm{K}$ and $385 \mathrm{~m} \mathrm{~s}^{-1}$ (in June), $898 / 566 \mathrm{~K}$ and $410 \mathrm{~m} \mathrm{~s}^{-1}$ (in September), and $1010 / 592 \mathrm{~K}$ and $383 \mathrm{~m} \mathrm{~s}^{-1}$ (in December), respectively.

Figure 2 shows temperature and horizontal wind distributions calculated with the whole atmosphere GCM and empirical models. Figure $2 \mathrm{a}$ is the same as Fig. 1d which presents temperature and horizontal wind on a constant-pressure surface of about $310 \mathrm{~km}$ altitude at 01:00 UT on 1 December. Figure $2 b$ is the same as Fig. 2a except for 5-day averages of the temperature and wind at 01:00 UT. Figure 2c shows temperature and horizontal wind at $310 \mathrm{~km}$ altitude at 01:00 UT on 1 December derived from empirical models of NRLMSISE-00 and HWM-93 (Hedin et al., 1996). Note that the strength of the maximum wind vector is different in each panel. The large-scale temperature distributions and wind patterns in Fig. 2a-c are quite similar to each other; high temperature regions are clearly seen at high-latitudes in summer (Southern) hemisphere and at dayside low-latitudes, while low temperature regions appear at high-latitudes in winter
(Northern) hemisphere. Some of the localised structures seen in Fig. 2a are smoothed out in Fig. 2b. The more smoothed structures are presented in Fig. 2c than those in Fig. 2b. In the GCM results (Fig. 2a), high temperature regions are seen in the midnight low-latitude region, particularly over Africa in the Southern Hemisphere. In this case, the GCM calculates a higher maximum temperature than that obtained from NRLMSISE-00 by $90 \mathrm{~K}$ (see Fig. $2 \mathrm{a}$ and c), while the minimum temperatures are almost the same (592 K by GCM and $593 \mathrm{~K}$ by NRLMSISE-00). In addition, the global mean temperature is calculated to be $788 \mathrm{~K}$ and $755 \mathrm{~K}$ by the GCM and NRLMSISE-00, respectively. The maximum wind velocity calculated by the GCM is also larger than that by HWM-93 by $139 \mathrm{~m} \mathrm{~s}^{-1}$. On the other hand, the maximum temperature and wind velocity shown in Fig. $2 b\left(967 \mathrm{~K}\right.$ and $318 \mathrm{~m} \mathrm{~s}^{-1}$ ) are closer to those shown in Fig. 2c.

Figure $3 \mathrm{a}$ and $\mathrm{b}$ is the same as Fig. $2 \mathrm{a}$ and $\mathrm{c}$, respectively, except for the temperature distribution and the display range: $50^{\circ}-90^{\circ}$ latitudes in the winter (Northern) hemisphere. The temperature distribution obtained from NRLMSISE-00 shows clear diurnal variation (Fig. 3b). On 


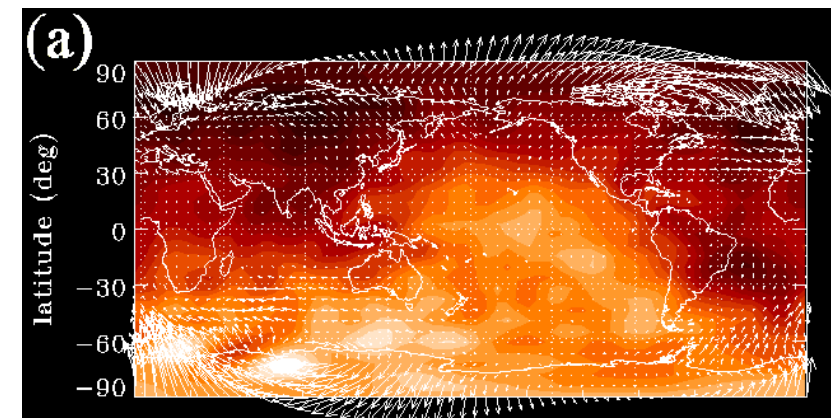

$0 \quad 30 \quad 60 \quad 90 \quad 120150180210240270300330360$

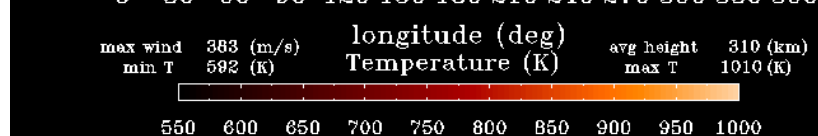

(b)

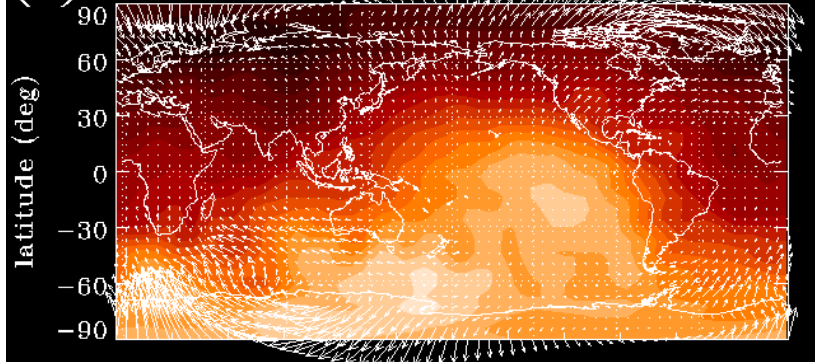

$\begin{array}{llllll}0 & 30 & 60 & 90 & 120150180210240270300330360\end{array}$
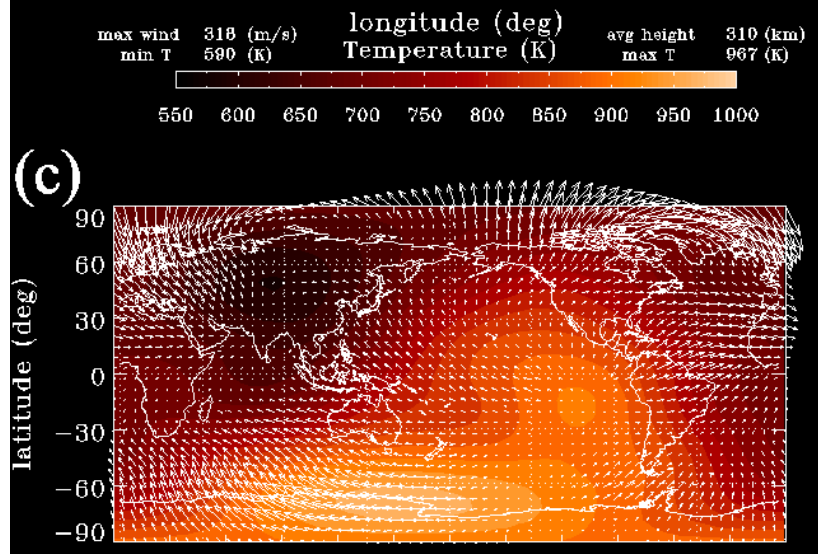

0 $\quad 30 \quad 60 \quad 90 \quad 120150180210240270300330360$

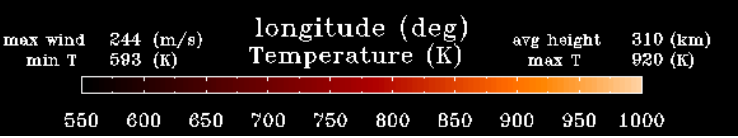

Fig. 2. The global distributions of temperature and horizontal wind obtained from (a) GCM calculations on a constant-pressure surface ( $\sim 310 \mathrm{~km}$ altitude) at 01:00 UT on 1 December, (b) 5-day averages of GCM calculations at 01:00 UT, and (c) the NRLMSISE-00 and HWM-93 empirical models. Note that the strength of the maximum wind vector is different in each panel.

the other hand, localised (small-scale) temperature structures are superimposed on the diurnal variation in the GCM results (Fig. 3a). These localised structures (high- and low-pressure areas in the thermosphere) vary from hour to hour in the

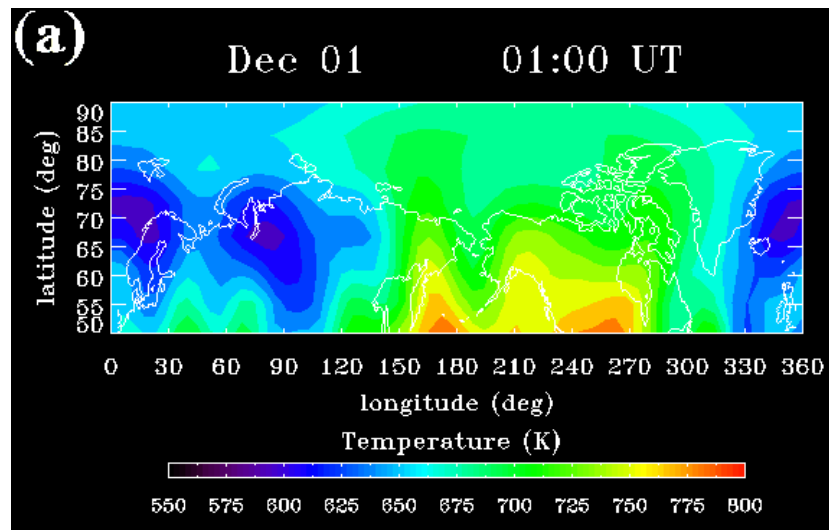

(b)

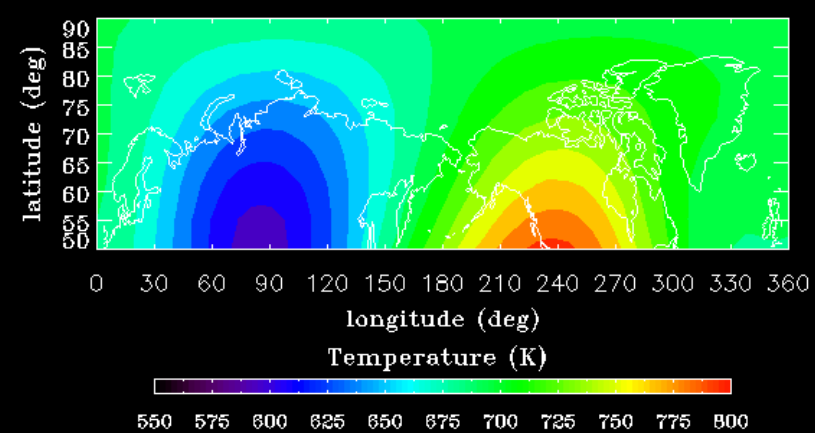

Fig. 3. Panels (a) and (b) are the same as Fig. 2a and c, respectively, except for temperature distributions in the $50^{\circ}-90^{\circ}$ latitude range in the Northern (winter) Hemisphere.

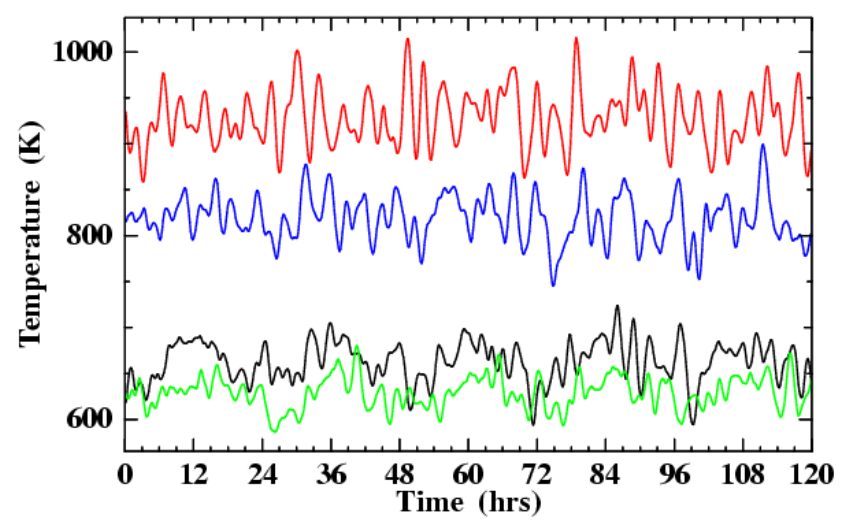

Fig. 4. Temperature variations at a constant-pressure surface ( $\sim 302-312 \mathrm{~km})$ at $76^{\circ} \mathrm{N}$ latitude and $17^{\circ} \mathrm{E}$ longitude during (a) 15 March (black line), (b) 1-5 June (red line), (c) 1-5 September (blue line), and (d) 1-5 December (green line). The calculated values are plotted every $10 \mathrm{~min}$. The values on the abscissa axis indicate hours from 00:00 UT on the 1st day of each month.

GCM simulations (not shown here). The localised structures seen in Figs. 1 and 3 seem to extend in about $20^{\circ}$ latitude and $30^{\circ}-60^{\circ}$ longitude ranges. 

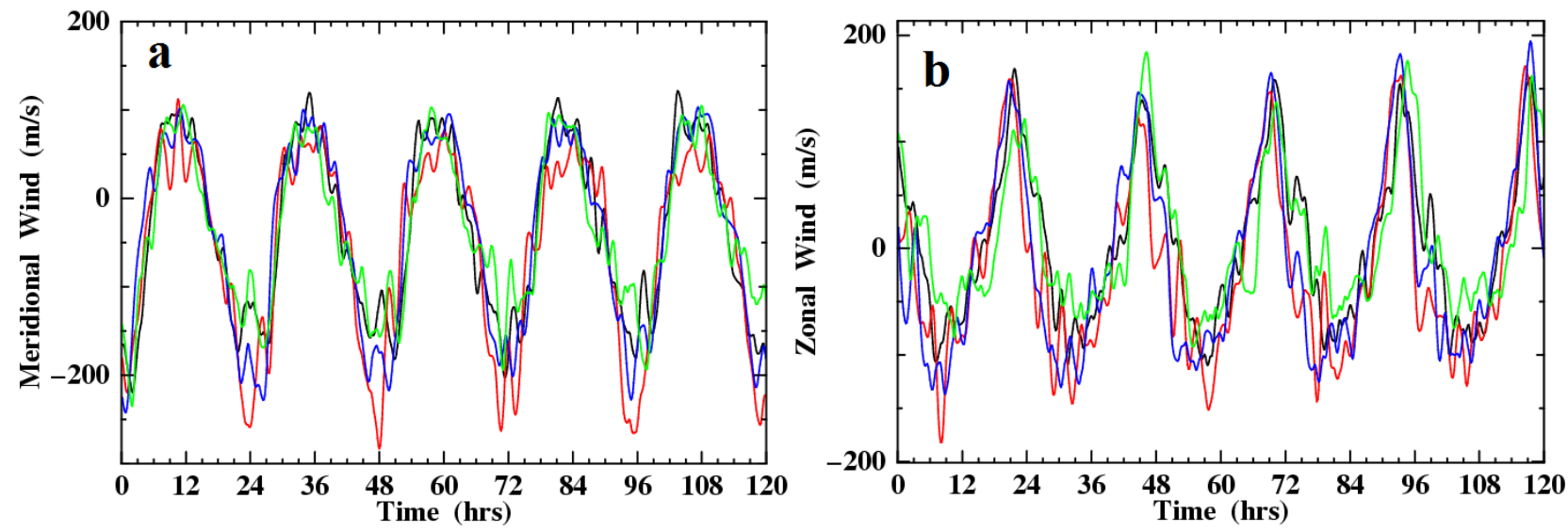

Fig. 5. Same as Fig. 4 except for (a) meridional wind and (b) zonal wind. The positive values indicate northward and eastward winds.

Figure 4 shows temporal variations of the thermospheric temperature calculated by the GCM for 1-5 March (black line), 1-5 June (red line), 1-5 September (blue line), and 1-5 December (green line). The values at a single point $\left(76^{\circ} \mathrm{N}\right.$ latitude and $17^{\circ} \mathrm{E}$ longitude) on a constant-pressure surface of about $302-312 \mathrm{~km}$ are plotted every $10 \mathrm{~min}$. For future comparisons of simulation results with observations, we choose the location at $76^{\circ} \mathrm{N}$ latitude and $17^{\circ} \mathrm{E}$ longitude, which is the nearest point to the European incoherent scatter Svalbard radar site. The values on the abscissa axis indicate hours from 00:00 UT on the 1st day of each month. The temperature in summer (June) shows the highest value among the four months while the temperature in winter (December) shows the lowest. The values in March and September are intermediates although features seen in winter and summer still remain in March and September, respectively. All the temperature variations include fluctuation components with periods of $2-3 \mathrm{~h}$. The diurnal temperature variation is indistinct in summer (June) since amplitudes of the fluctuation components are quite large, while temperature in winter (December) shows diurnal variations more clearly.

Figure 5 is the same as Fig. 4 except for the meridional (Fig. 5a) and zonal (Fig. 5b) winds. The meridional and zonal winds show significant diurnal variations because the ion drag force, which shows diurnal variation, accelerates the winds as well as the pressure gradient force. The fluctuation components with periods of $2-3 \mathrm{~h}$ are also seen both in the meridional and zonal winds. The amplitude of the diurnal variation in June (red line) is the largest, while that in December (green line) is the smallest. The strength of the antisunward flow (large negative values of the meridional winds) seems to be one of the characteristics of the seasonal wind variations.

Figure 6 shows temperature variations in the Northern (winter) Hemisphere during 1-5 December at $135^{\circ} \mathrm{E}$ longitude and $82^{\circ} \mathrm{N}, 70^{\circ} \mathrm{N}, 59^{\circ} \mathrm{N}, 48^{\circ} \mathrm{N}, 37^{\circ} \mathrm{N}, 25^{\circ} \mathrm{N}, 14^{\circ} \mathrm{N}$,

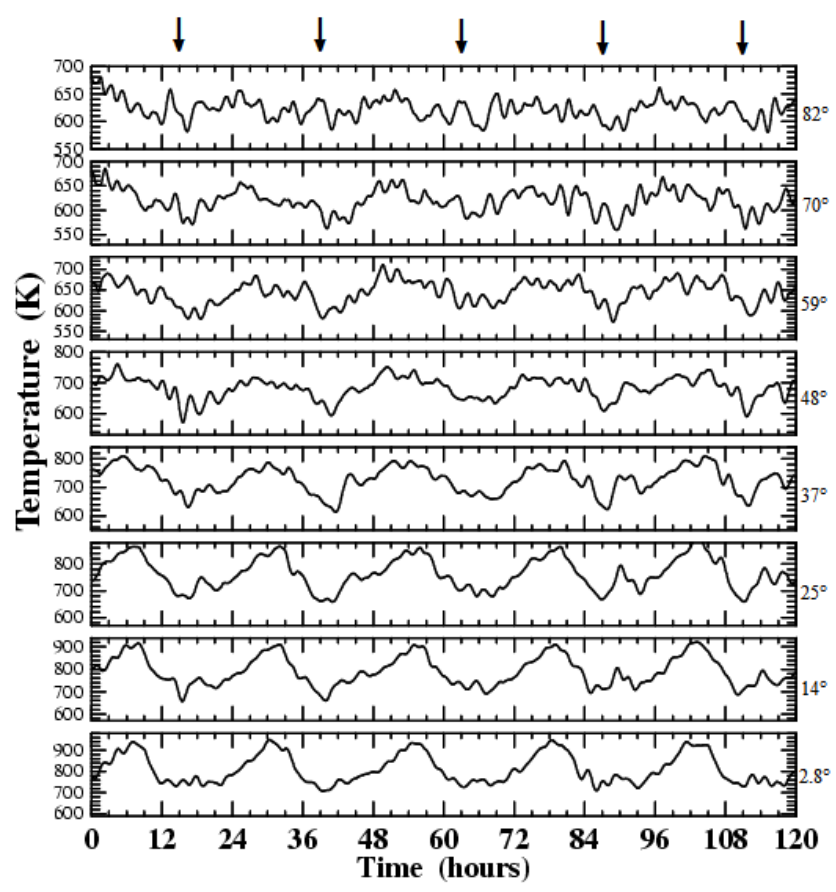

Fig. 6. Temperature variations at a constant-pressure surface ( $\sim 310 \mathrm{~km}$ ) during 1-5 December in the Northern (winter) Hemisphere at $135^{\circ} \mathrm{E}$ longitude and $82^{\circ} \mathrm{N}, 70^{\circ} \mathrm{N}, 59^{\circ} \mathrm{N}, 48^{\circ} \mathrm{N}, 37^{\circ} \mathrm{N}$, $25^{\circ} \mathrm{N}, 14^{\circ} \mathrm{N}$, and $2.8^{\circ} \mathrm{N}$ latitudes from the top to bottom, respectively. The values on the abscissa axis indicate hours from 00:00 UT on 1 December. The five arrows at the top of the figure denote the times corresponding to midnight (00:00 LT).

and $2.8^{\circ} \mathrm{N}$ latitudes from the top to bottom, respectively, in the same height region as Figs. 4 and 5. The values on the abscissa axis indicate time (hours) from 00:00 UT on 1 December. The five arrows at the top of Fig. 6 denote the times corresponding to midnight (00:00 LT). The output data from the GCM simulations are plotted every $10 \mathrm{~min}$. The diurnal 


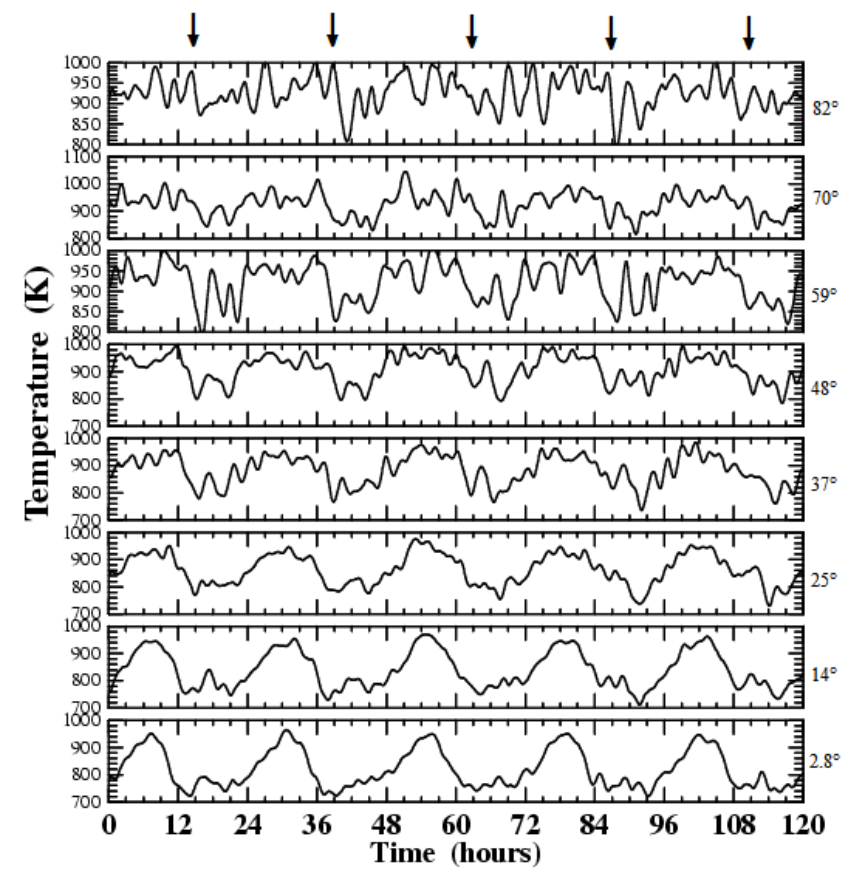

Fig. 7. Same as Fig. 6 except for the Southern (summer) Hemisphere.

temperature variation is not so clear at $82^{\circ} \mathrm{N}$ latitude. In the high-latitude region, fluctuations with periods of $2-3 \mathrm{~h}$ have large amplitudes, while the amplitudes of the fluctuations are small and the diurnal variations are clearly seen at mid- and low-latitudes. The temperature variations due to the midnight temperature maximum (MTM) appear after midnight in the low-latitude region. In particular, the MTMs with large amplitudes are seen at $14^{\circ} \mathrm{N}, 25^{\circ} \mathrm{N}$ and $37^{\circ} \mathrm{N}$ latitudes during about $87-93 \mathrm{~h}$; the amplitude is about $100 \mathrm{~K}$ at $25^{\circ} \mathrm{N}$ latitude. In the present simulations, the MTMs are clearly seen at the longitudes of Japan and Southeast Asia where tidal and gravity wave activities would be significant.

Figure 7 is the same as Fig. 6 except for the Southern (summer) Hemisphere. The diurnal temperature variation is indistinct at $82^{\circ} \mathrm{S}$ latitude because of large fluctuations with periods of 2-3 h. The amplitudes of the fluctuations in summer are much larger than those in winter. The diurnal temperature variation is also more indistinct in summer than in winter. The MTMs or similar structures with large amplitudes are seen at $2.8^{\circ} \mathrm{S}, 14^{\circ} \mathrm{S}, 25^{\circ} \mathrm{S}, 37^{\circ} \mathrm{S}$, and $48^{\circ} \mathrm{S}$ latitudes during about 15-21, 39-42, 63-69, and 87-93 h; the amplitudes are several 10 s to about $150 \mathrm{~K}$. It is difficult to identify the MTMs in the mid- and high-latitude regions because the temperature fluctuations with periods of about $2-3 \mathrm{~h}$ are significant. In the present case, the MTMs in summer appear more frequently (almost every day) with larger amplitudes than in winter. In addition, the MTMs seem to appear earlier at night for summer than for winter.

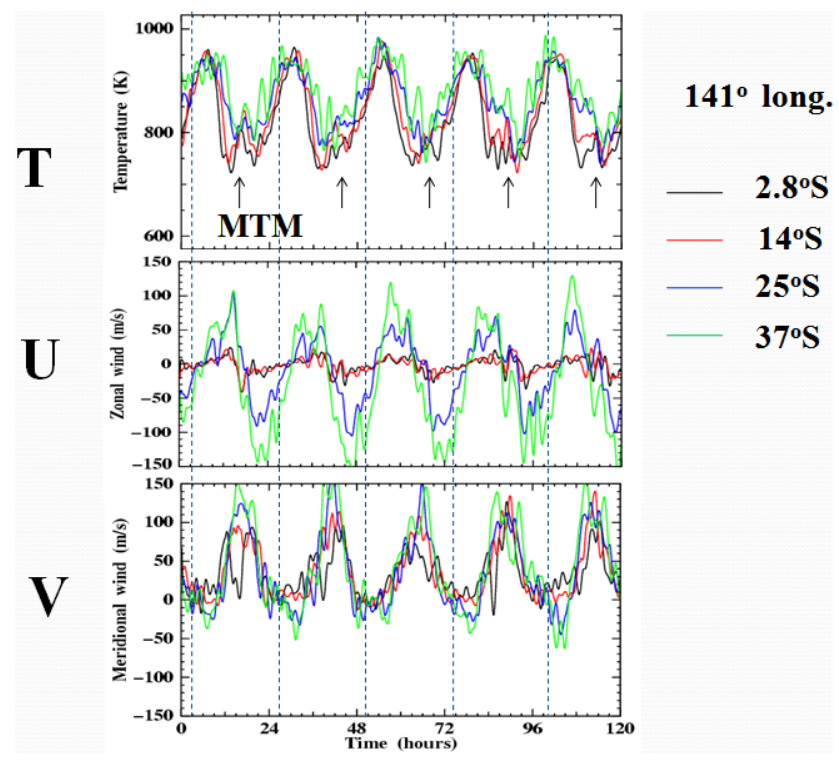

Fig. 8. Temperature and horizontal wind variations at a constantpressure surface $(\sim 310 \mathrm{~km})$ during $1-5$ December in the Southern (summer) Hemisphere at $141^{\circ} \mathrm{E}$ longitude and $37^{\circ} \mathrm{S}$ (green line), $25^{\circ} \mathrm{S}$ (blue line), $14^{\circ} \mathrm{S}$ (red line), and $2.8^{\circ} \mathrm{S}$ (black line) latitudes. The values on the abscissa axis indicate hours from 00:00 UT on 1 December. The vertical dashed lines denote the times corresponding to local noon (12:00 LT).

In order to capture the MTMs more clearly, the temperature and horizontal wind variations during 1-5 December at $141^{\circ} \mathrm{E}$ longitude and $37^{\circ} \mathrm{S}$ (green line), $25^{\circ} \mathrm{S}$ (blue line), $14^{\circ} \mathrm{S}$ (red line), and $2.8^{\circ} \mathrm{S}$ (black line) latitudes are shown in Fig. 8. The arrows in the top panel indicate the MTMs. The amplitudes of the MTMs are $\sim 10 \mathrm{~s}-100 \mathrm{~K}$ in this case. The direction of the zonal wind changes from positive value to negative one when the MTM appears. The meridional winds are larger at the higher latitudes during the MTM appearance. These indicate the convergence of the horizontal winds which would have contributions to formation of the MTM. Although the meridional wind shows the local time variation with small-scale fluctuations, the direction of the meridional wind does not change in association with the MTM appearance in this case.

Figure 9 shows temperature and horizontal wind distributions at 16:00 UT on 1 December on a constant-pressure surface of about $311 \mathrm{~km}$ altitude: the same as Fig. 1d except for UT and the colour scale of the contour map. The MTM is clearly seen in the low-latitude region between about $140^{\circ}-$ $170^{\circ}$ longitude ( $\sim$ 01:00-03:00 LT) in the Southern (summer) Hemisphere. The MTM shown in Fig. $8(\sim 14-20 \mathrm{~h})$ is a part of the MTM seen in Fig. 9. The convergent winds are seen around the MTM. In addition, strong anti-sunward wind (or equatorward wind) forms a stream of warm air from high to low-latitude region. Both the wind convergence and stream of warm air would have contributions to formation of the MTM. 


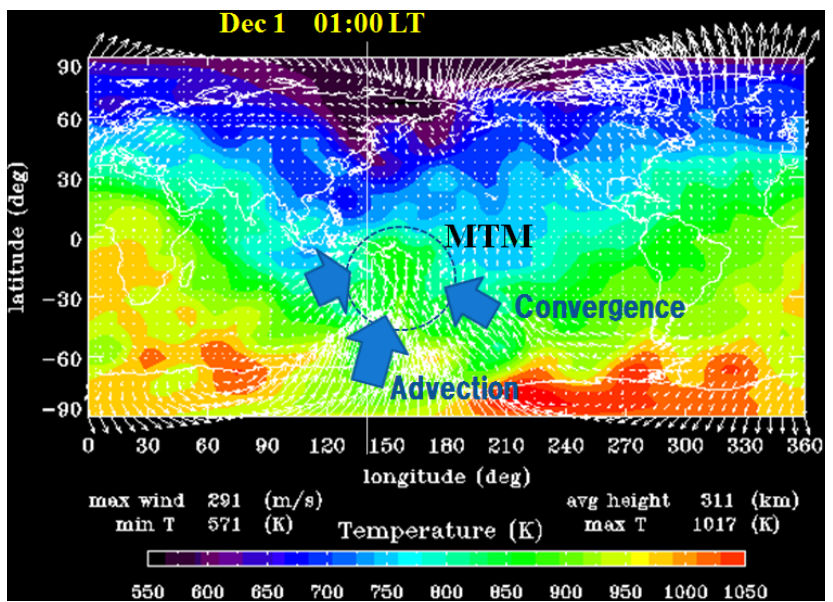

Fig. 9. Same as Fig. 1d except for 16:00 UT on 1 December and the colour scale of the contour map.

\section{Discussion}

As seen in Figs. 1 and 2, the GCM results represent well the characteristics of the global (large-scale) temperature and horizontal wind patterns at each season. In addition, the GCM describes localised temperature structures while an empirical model of NRLMSISE-00 shows the smoothed temperature structure which comes from statistical averages of data obtained from various observations (Picone et al., 2002). Since the GCM includes all the atmospheric regions, the lower atmospheric effects can reproduce the localised high and low temperature areas in the upper atmosphere. These localised temperature structures produce large pressure gradients, which drive strong winds, in the GCM results. Fujiwara and Miyoshi (2009) investigated the lower atmospheric effects on producing the disturbances in the upper thermosphere from the GCM simulations. They compared usual simulation results with results from simulations without the lower atmospheric effects by setting zero-wind and global mean temporally-invariant temperature below about $80 \mathrm{~km}$. The more smoothed temperature structure, which was similar to one from an empirical model shown in Fig. 2c, was obtained in the case of simulations without the lower atmospheric effects. Some of the localised structures are also smoothed out by averaging the GCM data as shown in Fig. 2b. This suggests that day-to-day variations of the temperature and wind, which are caused by the lower atmospheric effects, would be essential for localised temperature and wind structures in the upper atmosphere.

The origins of the disturbances, which show day-to-day variations, should be investigated more in detail in the future works. The gravity waves are the candidate for one of the origins. Some of the gravity waves originated from the lower atmosphere should be largely prevented from propagating to the upper atmosphere. On the other hand, as suggested by Vadas and Fritts (2006), the short-period, long verticalwavelength portions of gravity waves generated by tropospheric convection would propagate into the thermosphere. From numerical simulations with the higher resolution version of the whole atmosphere GCM, Miyoshi and Fujiwara (2008) showed the similar feature of the gravity waves to Vadas and Fritts (2006). In addition, Miyoshi and Fujiwara (2008) also suggested two main source regions for the shortperiod gravity waves; the gravity waves would be generated in the tropical troposphere and/or secondary gravity waves would be generated due to breaking of gravity waves in the mesosphere. The GCM simulations by Miyoshi and Fujiwara (2008) showed significant fluctuations with periods of $1-3 \mathrm{~h}$ above $120 \mathrm{~km}$. In the present study, fluctuations with periods of $2-3 \mathrm{~h}$, which would originate from the gravity waves, are superimposed on the large-scale temperature structure in the polar upper thermosphere. In addition to the day-night (diurnal) temperature structure, some tidal components, e.g., semidiurnal and terdiurnal tides, would have contributions to formation of the large-scale temperature structure which is different from that obtained from NRLMSISE-00. The temperature fluctuations, which vary from hour to hour, would be observed as temporal variations with periods of $2-3 \mathrm{~h}$ at a single station as shown in Fig. 4. In the low-latitude regions, the midnight temperature maximum (MTM) is clearly seen as a result from the tidal effects. The morphological features of the temperature in the upper thermosphere are characterised by fluctuations with periods of $2-3 \mathrm{~h}$ (gravity wave effecs) at high-latitudes and the MTM (tidal effects) at low-latitudes in the present study. Although we have checked for obvious possible numerical mistakes, e.g., steep artificial variations, by using both high and coarse resolution versions of the GCM, the GCM simulations would have limitations for representing actual phenomena depending on parameterisations and/or assumptions in the model. Since we would cut away a portion of some phenomena, we should make comparisons between observations and the GCM results.

Killeen et al. (1995) observed the polar cap temperature and winds in the upper thermosphere $(\sim 240 \mathrm{~km})$ with the Fabry-Perot interferometer (FPI) at Thule, Greenland (76.5 ${ }^{\circ} \mathrm{N}$ latitude, $69.0^{\circ} \mathrm{W}$ longitude) during the solar minimum and maximum winter periods. They showed temporal temperature variations with periods of $2-3 \mathrm{~h}$. The diurnal temperature variation was more clearly seen during the solar maximum than the solar minimum periods because the daynight heat advection, which was more significant during the solar maximum period, would be a dominant heat source in the winter polar cap region of the upper thermosphere. In the present GCM simulations, the heat advection is important for causing the diurnal temperature variation in winter while the solar EUV heating, which has less local time dependence, is the dominant heat source in the summer polar cap region. This would cause the seasonal dependence of the diurnal temperature variation as shown in Fig. 4. 
The FPI observations by Killeen et al. (1995) showed that the typical averaged anti-solar wind speeds over Thule during the early solar minimum period were $\sim 200 \mathrm{~m} \mathrm{~s}^{-1}$. The present GCM results shown in Fig. 5a are almost in agreement with the FPI wind observations. However, the averaged temperature obtained from the FPI observations showed higher values than the GCM results although the GCM results seem to be within the range of the observations. The temperature obtained from the FPI observations was also higher than that by an empirical model which provides higher temperature than the GCM results. The discrepancies between temperatures from the FPI observations, empirical model, and GCM may be caused by local heat sources, e.g., localised Joule heating and/or particle precipitation which are not included in the GCM and whose effects are smoothed out in the empirical model. Recently, Anderson et al. (2009) showed thermospheric winds and temperatures observed at Mawson, Antarctica in 2007 (low solar activity). They compared the observations with results from the Coupled Thermosphere/Ionosphere Plasmasphere model (CTIP) and NRLMSISE-00. Although the observed temperatures were well modelled during geomagnetically quiet periods, the observed temperatures were consistently higher than NRLMSISE-00 predicted, by up to $100 \mathrm{~K}$. CTIP temperatures better matched observations later in the night; however, the modelled ones seem to be smaller than the observed ones by several $10 \mathrm{~s} \mathrm{~K}$ on average. The examples of temperature observations in the polar thermosphere are still few. In addition, the FPI temperature observations have uncertainty by several $10 \mathrm{~s} \mathrm{~K}$. We should continue more observations in the polar cap thermosphere, modelling studies, and comparison of them.

Although the Joule heating can be an important heat source which causes temporal temperature variations, we assume the same geomagnetic activity for each simulation to investigate fundamental features (or basic states) of temporal temperature variations during geomagnetically quiet periods as mentioned above. Recently, Griffin et al. (2008) obtained the thermospheric winds and temperatures on 15 March 2007 (low solar activity) from the oxygen 630-nm emisson observations with a Scanning Doppler Imager (SCANDI). They showed mesoscale thermospheric structures which would result from particle precipitation, Joule heating, and other effects. In order to interpret such mesoscale temperature variations through ion-neutral coupling, we should also understand fundamental features of thermospheric temperature variation caused by the lower atmospheric effects in the first instance.

Our GCM simulations show that the amplitudes of fluctuation components with $2-3 \mathrm{~h}$ periods are smaller in lowlatitude than in high-latitude, which contributes to significant day-night temperature variation in low-latitude. The fluctuations with large amplitudes in high-latitude, particularly in the polar cap region, seen in the GCM results seem to be consistent with results from observations by Innis and
Conde (2001) although Innis and Conde (2001) focused on fluctuations with smaller spatio-temporal scales than those in the GCM results. The spatio-temporal variations of temperature in the polar cap region should be investigated more from radar and optical observations and GCM simulations in various cases. In particular, the upper thermosphere temperature data in the summer polar region are very poor because the main sources of observations come from optical instruments which are restricted to nighttime measurements. The ion temperature observations with incoherent scatter radar, e.g., European Incoherent Scatter radar (EISCAT radar), will be effective for inferring the neutral temperature and/or monitoring the activities of the atmospheric gravity waves from below (e.g., Shibata and Schlegel, 1993).

The midnight temperature maximum (MTM) is one of the typical temperature structures in the low-latitude upper thermosphere. The present GCM simulations clearly show the MTM with significant day-to-day variations (see Figs. 6 and 7). The calculated temperature oscillates with high frequencies, suggesting the superposition of the semidiurnal and higher order tidal modes as pointed by early studies (e.g., Herrero and Spencer, 1982). The latitudinally-extended MTMs are clearly seen particularly during $87-93 \mathrm{~h}$ in Fig. 6, which is also in agreement with observations presented by Herrero and Spencer (1982).

The amplitudes of the MTM simulated with previous GCMs were much smaller than those observed (e.g., Colerico and Mendillo, 2002). In the present study, the amplitudes of the MTM are calculated to be several 10s-150 K, which are almost consistent with the MTM amplitudes obtained from observations (e.g., Faivre et al., 2006; Meriwether et al., 2008). The previous upper atmosphere GCMs set the lower boundaries in the altitude range of about 30$100 \mathrm{~km}$. In the previous GCMs, tidal effects were imposed at the lower boundaries assuming dominant diurnal and semidiurnal tidal modes. Since the GCM used in the present study covers all the atmospheric regions, the atmospheric tides with various modes are generated in the GCM. These tides seem to contribute to formation of the MTMs with large amplitudes.

The GCM simulations show wind convergence around the MTM region. In particular, the meridional wind would have significant contributions to formation of the MTM through adiabatic compression heating and advection of warm air from higher latitudes. The flow channel from high to lowlatitude region and wind convergence are clearly seen in the vicinity of the MTM region in Fig. 9. The pressure bulge in association with the MTM does not cause abatement of the equatorward wind. Maruyama et al. (2008) inferred the thermospheric meridional winds from ionospheric height variations observed with the equatorial ionosonde network (Southeast Asia Low-latitude Ionospheric Network: SEALION). They found the wind variations with a period of 6-8 $\mathrm{h}$ and clear correlation between the convergent wind and the MTM. They also mentioned that they did not find any evidence showing abatement/reversal of the equatorward 


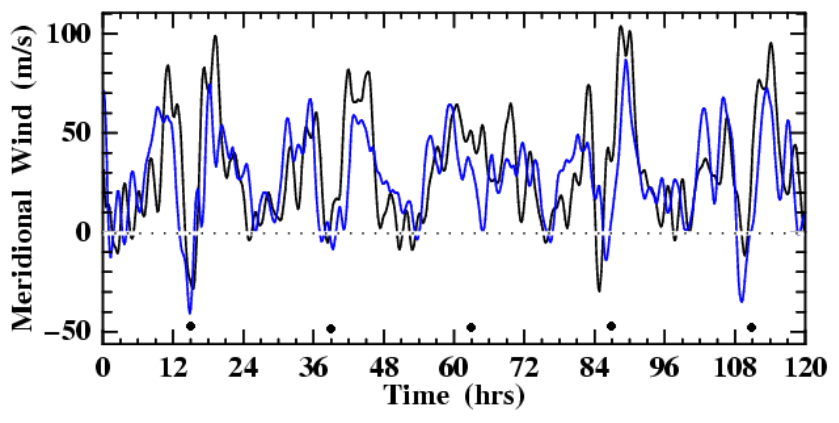

Fig. 10. Meridional wind variations at a constant-pressure surface ( $\sim 310 \mathrm{~km}$ ) during 1-5 December in the Northern (winter) Hemisphere at $141^{\circ} \mathrm{E}$ longitude and $14^{\circ} \mathrm{N}$ (blue line), and $2.8^{\circ} \mathrm{N}$ (black line) latitudes. The five circle dots in the panel indicate the times of midnight. Positive values indicate northward winds.

wind associated with the pressure bulge cause by the MTM. The present GCM results are in agreement with Maruyama et al. (2008) although some previous studies ascribed the wind variations to the pressure bulge associated with the MTM (see references in Maruyama et al., 2008).

Figure 10 shows the meridional wind variations at a constant-pressure surface $(\sim 310 \mathrm{~km})$ during $1-5$ December in the Northern (winter) Hemisphere at $141^{\circ} \mathrm{E}$ longitude and $14^{\circ} \mathrm{N}$ (blue line), and $2.8^{\circ} \mathrm{N}$ (black line) latitudes. The circle dots in the panel denote the times of midnight. The meridional wind reversals/abatements are seen at around midnight. For example, the northward wind abated after 11:00-12:00 UT (20:00-21:00 LT) and reversed to southward at 13:00-14:00 UT (22:00-23:00 LT). After about midnight, the wind direction again reversed. The similar wind variation to the above is seen at $2.8^{\circ} \mathrm{S}$ (shown in Fig. 8) although the southward reversal is very small. These are consistent with observations by Maruyama et al. (2008). These wind reversals/abatements seen in the GCM results are explained by local time variations of airflow pattern in the lowlatitude region. As seen in Fig. 9, some airstreams converge on the MTM region. In the summer hemisphere (Southern Hemisphere in Fig. 9), the wind reversal can hardly occur since the meridional wind due to e.g., day-to-night flow or tidal flow directs almost always equatorward (northward) in the nighttime (see Figs. 8 and 9). On the other hand, although the tidal flow directs poleward (northward) in the evening hours, the meridional flow directs equatorward (southward) at around midnight in the winter (Northern) hemisphere (see Figs. 9 and 10). We will show more details of the MTM and wind variations simulated by the GCM in our future papers.

\section{Conclusions}

We investigated temperature and wind variations in the upper thermosphere by using a whole atmosphere GCM which includes all the atmospheric regions from the ground to the exobase. This GCM enables us to simulate temperature, wind, and composition variations, which originate from the lower atmosphere, from hour to hour in the upper thermosphere.

The large-scale temperature distributions simulated by the GCM are consistent with those obtained from an empirical model of NRLMSISE-00. The GCM results also represent localised temperature structures superimposed on the largescale day-night temperature structure. These temperature structures seem to enlarge and/or lower the maximum and minimum temperatures. In addition, the localised temperature structures produce large pressure gradients which derive strong neutral winds.

In the polar cap region of the upper thermosphere, the daynight temperature variation is not clearly seen in the GCM results because of modulation by localised temperature structures which vary from hour to hour, while the winds show significant diurnal variations. The spatio-temporal variations of these localised structures would be observed as temporal variations with periods of $2-3 \mathrm{~h}$ at a single station. The amplitudes of the localised temperature structures (or temporal variations with periods of $2-3 \mathrm{~h}$ ) are smaller in the middle- and low-latitude regions than in the high-latitude region. The day-night temperature difference (or diurnal temperature variation) is more significant in the middle- and lowlatitude regions than in the high-latitude region. The diurnal temperature variation in the high-latitude region is more significant in winter than in summer if the high-latitude convection electric field is the same in both cases.

The midnight temperature maximum (MTM) is clearly seen in the GCM results. The MTMs calculated here show significant day-to-day variations. The MTMs shown by the present GCM simulations have large amplitudes of several 10 s to about $150 \mathrm{~K}$. These seem to depend on the tidal waves in the GCM simulations; the tidal waves with various modes are generated in the GCM which covers all the atmospheric regions rather than being generated by an imposed lower boundary. The MTMs in summer appear more frequently (almost every day) with larger amplitudes than in winter in the present cases. In addition, the MTM appearance seems to occur earlier at night for summer than for winter.

The GCM simulations show wind convergence around the MTM region. In particular, the meridional wind would have significant contributions to formation of the MTM through adiabatic compression heating and advection of warm air from higher latitudes. The flow channel from the highlatitude to the MTM region is found as well as wind convergence due to tidal effects. The meridional wind reversals/abatements in association with the pressure bulge due to the MTM are not found in the GCM results. The wind reversals/abatements seen in the winter hemisphere are explained by local time variation of airflow pattern in the low-latitude region. 
Acknowledgements. This work was supported in part by Grant-inAid for Scientific Research C (20540435), B (17340140), and Scientific Research on Innovative Areas (20200047), and the Global COE program "Global Education and Research Center for Earth and Planetary Dynamics" at Tohoku University by the Ministry of Education, Science, Sports and Culture, Japan. A part of this work was also supported by the joint research program of the Solar-Terrestrial Environment Laboratory, Nagoya University. The empirical models of NRLMSISE-00 and HWM-93 are provided by NSSDC/NASA.

Topical Editor M. Pinnock thanks M. Conde and another anonymous referee for their help in evaluating this paper.

\section{References}

Anderson, C., Conde, M., Dyson, P., Davies, T., and Kosch, M. J.: Thermospheric winds and temperatures above Mawson, Antarctica, observed with an all-sky imaging, Fabry-Perot spectrometer, Ann. Geophys., 27, 2225-2235, 2009, http://www.ann-geophys.net/27/2225/2009/.

Colerico, M. J. and Mendillo, M.: The current state of investigations regarding the thermospheric midnight temperature maximum (MTM), J. Atmos. Solar-Terr. Phys., 64, 1361-1369, 2002.

Faivre, M., Meriwether, J. W., Fesen, C. G., and Biondi, M. A.: Climatology of the midnight temperature maximum phenomenon at Arequipa, Peru, J. Geophys. Res., 111, A06302, doi:10.1029/2005JA011321, 2006.

Ford, E. A. K., Aruliah, A. L., Griffin, E. M., and McWhirter, I.: Statistical analysis of thermospheric gravity waves from FabryPerot Interferometer measurements of atomic oxygen, Ann. Geophys., 26, 29-45, 2008,

http://www.ann-geophys.net/26/29/2008/.

Forbes, J. M., Bruinsma, S. L., Miyoshi, Y., and Fujiwara, H.: A solar terminator wave in thermosphere neutral densities measured by the CHAMP satellite, Geophys. Res. Lett., 35, L14802, doi:10.1029/2008GL034075, 2008.

Fujiwara, H. and Miyoshi, Y.: Characteristics of the largescale traveling atmospheric disturbances during geomagnetically quiet and disturbed periods simulated by a whole atmosphere general circulation model, Geophys. Res. Lett., 33, L20108, doi:10.1029/2006GL027103, 2006.

Fujiwara, H. and Miyoshi, Y.: Global structure of large-scale disturbances in the thermosphere produced by effects from the upper and lower regions: simulations by a whole atmosphere GCM, Earth, Planets Space, 61, 463-470, 2009.

Fujiwara, H., Kataoka, R., Suzuki, M., Maeda, S., Nozawa, S., Hosokawa, K., Fukunishi, H., Sato, N., and Lester, M.: Electromagnetic energy deposition rate in the polar upper thermosphere derived from the EISCAT Svalbard radar and CUTLASS Finland radar observations, Ann. Geophys., 25, 2393-2403, 2007, http://www.ann-geophys.net/25/2393/2007/.

Fuller-Rowell, T. J. and Evans, D. S.: Height-integrated Pedersen and Hall conductivity patterns inferred from the TIROS-NOAA satellite data, J. Geophys. Res., 92, 7606-7618, 1987.

Griffin, E. M., Aruliah, A. L., McWhirter, I., Yiu, H.-C. I., Charalambous, A., and McCrea, I.: Upper thermospheric neutral wind and temperature measurements from an extended spatial field, Ann. Geophys., 26, 2649-2655, 2008, http://www.ann-geophys.net/26/2649/2008/.
Hedin, A. E., Fleming, E. L., Manson, A. H., Schmidlin, F. J., Avery, S. K., Clark, R. R., Franke, S. J., Fraser, G. J., Tsuda, T., Vial, F., and Vincent, R. A.: Empirical wind model for the upper, middle and lower atmosphere, J. Atmos. Terr. Phys., 58, 14211447, 1996.

Herrero, F. A. and Spencer, N. W.: On the horizontal distribution of the equatorial thermospheric midnight temperature maximum and its seasonal variation, Geophys. Res. Lett., 9, 1179-1182, 1982.

Innis, J. L. and Conde, M.: Thermospheric vertical wind activity maps derived from Dynamics Explorer-2 WATS observations, Geophys. Res. Lett., 28, 3847-3850, 2001.

Killeen, T. L., Won, Y.-I., Niciejewski, R. J., and Burns, A. G.: Upper thermosphere winds and temperatures in the geomagnetic polar cap: Solar cycle, geomagnetic activity, and interplanetary magnetic field dependences, J. Geophys. Res., 100, 21327 21342, 1995.

Lühr, H., Rother, M., Kohler, W., Ritter, P., and Grunwaldt, L.: Thermospheric up-welling in the cusp region: Evidence from CHAMP observations, Geophys. Res. Lett., 31, L06805, doi:10.1029/2003GL019314, 2004.

Maruyama, T., Saito, S., Kawamura, M., and Nozaki, K.: Thermospheric meridional winds as deduced from ionosonde chain at low and equatorial latitudes and their connection with midnight temperature maximum, J. Geophys. Res., 113, A09316, doi:10.1029/2008JA013031, 2008.

Meriwether, J., Faivre, M., Fesen, C., Sherwood, P., and Veliz, O.: New results on equatorial thermospheric winds and the midnight temperature maximum, Ann. Geophys., 26, 447-466, 2008, http://www.ann-geophys.net/26/447/2008/.

Miyahara, S., Yoshida, Y., and Miyoshi, Y.: Dynamic coupling between the lower and upper atmosphere by tides and gravity waves, J. Atmos. Terr. Phys., 55, 1039-1053, 1993.

Miyoshi, Y.: Numerical simulation of the 5-day and 16-day waves in the mesopause region, Earth, Planets Space, 51, 763-772, 1999.

Miyoshi, Y. and Fujiwara, H.: Day-to-day variations of migrating diurnal tide simulated by a GCM from the ground surface to the exobase, Geophys. Res. Lett., 30, 1789, doi:10.1029/2003GL017695, 2003.

Miyoshi, Y. and Fujiwara, H.: Excitation mechanism of intraseasonal oscillation in the equatorial mesosphere and lower thermosphere, J. Geophys. Res., 111, D14108, doi:10.1029/2005JD006993, 2006.

Miyoshi, Y. and Fujiwara, H.: Gravity Waves in the Thermosphere Simulated by a General Circulation Model, J. Geophys. Res., 113, D01101, doi:10.1029/2007JD008874, 2008.

Oberheide, J. and Forbes, J. M.: Tidal propagation of deep tropical cloud signatures into the thermosphere from TIMED observations, Geophys. Res. Lett., 35, L04816, doi:10.1029/2007GL032397, 2008.

Picone J. M., Hedin, A. E., Drob, D. P., and Aikin, A. C.: NRLMSISE-00 empirical model of the atmosphere: Statistical comparisons and scientific issues, J. Geophys. Res., 107, 1468, doi:10.1029/2002JA009430, 2002.

Roble, R. G. and Ridley, E. C.: An auroral model for the NCAR thermospheric general circulation model (TGCM), Ann. Geophys., 54, 369-382, 1987.

Rishbeth, H., Müller-Wodarg, I. C. F., Zou, L., Fuller-Rowell, T. J., 
Millward, G. H., Moffett, R. J., Idenden, D. W., and Aylward, A. D.: Annual and semiannual variations in the ionospheric F2-layer: II. Physical discussion, Ann. Geophys., 18, 945-956, 2000 ,

http://www.ann-geophys.net/18/945/2000/.

Shepherd, S. G., Ruohoniemi, J. M., and Greenwald, R. A.: Direct measurements of the ionospheric convection variability near the cusp/throat, Geophys. Res. Lett., 30, 2109, doi:10.1029/2003GL017668, 2003.
Shibata, T. and Schlegel, K.: Vertical structure of AGW associated ionospheric fluctuations in the E- and lower F-region observed with EISCAT - a case study, J. Atmos. Terr. Phys., 55 , 739-749, 1993.

Vadas, S. L. and Fritts, D. C.: Influences of solar variability on gravity wave structure and dissipation in the thermosphere from tropospheric convection, J. Geophys. Res., 111, A10S12, doi:10.1029/2005JA011510, 2006.

Volland, H.: Models of the global electric fields within the magnetosphere, Ann. Geophys., 31, 159-173, 1975. 